\title{
Incentive Stackelberg Strategies for a Dynamic Game on Terrorism
}

\author{
Doris A. Behrens \\ Institute for Mathematical Methods in Economics, ORDYS \\ Vienna University of Technology \\ 1040 Vienna, Austria \\ and \\ Department of Economics \\ Alps Adriatic University of Klagenfurt \\ 9020 Klagenfurt, Austria \\ Jonathan P. Caulkins \\ H. John Heinz III School of Public Policy and Management \\ Carnegie Mellon University, Pittsburgh, PA 15213 \\ and \\ Qatar Campus, PO Box 24866, Doha, Qatar \\ Gustav Feichtinger and Gernot Tragler \\ Institute for Mathematical Methods in Economics, ORDYS \\ Vienna University of Technology \\ 1040 Vienna, Austria \\ tragler@eos.tuwien.ac.at
}

\begin{abstract}
This paper presents a dynamic game model of international terrorism. The time horizon is finite, about the size of one presidency, or infinite. Quantitative and qualitative analysis of incentive Stackelberg strategies for both decision-makers of the game ("The West" and "International Terror Organization") allows statements about the possibilities and limitations of terror control interventions. Recurrent behavior is excluded with monotonic variation in the frequency of terror attacks whose direction depends on when the terror organization launches its terror war. Even optimal pacing of terror control operations does not greatly alter the equilibrium of the infinite horizon game, but outcomes from the West's perspective can be greatly improved if the game is only "played" for brief periods of time and if certain parameters could be influenced, notably those pertaining to the terror organization's ability to recruit replacements.
\end{abstract}




\section{Introduction}

International terrorism is by any measure a principal concern of policy makers and a complex issue. This paper complements and extends the work of Keohane and Zeckhauser [18], Kaplan et al. [17], and Caulkins et al. [6] among others by developing incentive Stackelberg strategies for a dynamic "terror game" model. This model aims to shed light on the question of how best to prosecute the "war on terror", specifically terror control operations intended to preempt or deter terror attacks.

The premise of the model presented here is that terror attacks (such as suicide bombings) are produced by a "stock of terrorists" [18] that represents the strength of a specific adversary (such as Al-Qaeda). Their/its "power" reflect/s some combination of human resources, financial resources, technical sophistication (particularly of weapons and weapons delivery), and sympathy/public support, particularly among the non-terrorist population within which terrorists are embedded.

The modeling is motivated by the September $11^{\text {th }}$ attacks in the US, the March $11^{\text {th }}$ attacks in Madrid, the July $7^{\text {th }}$ attacks in London, and associated events. We will refer to the decision-maker or player on the terrorist side as "ITO" simply as an abbreviation of some International Terror Organization. ITO's opponents are assumed to include the West and certain Arab regimes variously labeled as "moderate", "secular", "proWestern", or "authoritarian". For ease of exposition, we will refer to ITO's opponent simply as "the West".

The structure of this paper is as follows. Section 2 is devoted to a crucial ingredient for the model discussed here, namely the "two-edged effect" of (potentially inflammatory) terror control activities. The "game on terror" is then presented in section 3. Section 4 includes the derivation of the asymmetric noncooperative strategies for the West and ITO for a finite time horizon. Parameterizing the model allows us to illustrate our results in section 5, including a thorough sensitivity analysis yielding important insights about possibilities and limitations of terror control policies. Section 6 concludes the paper with an outlook to further research.

\section{The Two-Edged Effect of Terror Control Interventions}

Each decision-maker in the "game-theoretic" interaction in the field of international terrorism has access to (at least) one instrument for altering the status quo. ITO can choose the rate at which it commits terror attacks. The West can choose the intensity with which it attacks ITO (to prevent terror attacks). ${ }^{1}$

\footnotetext{
${ }^{1}$ Our analysis focuses on these two interventions. Defensive aspects of homeland security operations are not modeled explicitly. When the West exercises its control
} 
At times of "war", attacks by both sides reduce the stock of terrorists (as opposed to "peacetime" when neither side is making attacks). Attacks by the West kill, capture, or incapacitate terrorists directly; that is their purpose. ITO suicide attacks also obviously kill ITO members. Even nonsuicide attacks will tend to reduce the size of ITO because every attack exposes the organization to law enforcement risk and its operatives to an increased likelihood of imprisonment and/or death. The more aggressively the West is prosecuting its terror control campaign, the higher is the number of ITO operatives lost per successful attack. Moreover, the higher the intensity of terror control interventions, the more resources that can be devoted to investigating the aftermath of an attack by creating better opportunities for interrogations. These might in turn provide information about other ITO targets and operatives, so that subsequent suicide attackers can be stopped beforehand. So, the higher the West's intensity of terror control measures, the more attacks that ITO has to launch to produce a single successful operation. Hence, it is more costly for ITO (in terms of personnel losses) to attack when the West is in a counter-terror posture than when it is passive.

New terrorists are recruited by existing terrorists. Accordingly, when ITO is small, the growth rate ought to be increasing in the current number of terrorists. Yet, growth is not exponential and unbounded. At some point, growth per current member should slow down because of limits on the number of potential recruits, limits on the capacity of ITO to train and absorb new recruits, etc.

There is, however, one further dynamic that may be important, namely the possibility that aggressive attacks by the West generate resentment among the populations from which ITO seeks recruits. Heymann [16] mentions this possibility and notes (p.62) that "recruitment to the Irish Republican Army (IRA) increased sharply during some periods of overly vigorous British action against suspects." That is, terror control attacks by the West may have the direct benefit of eliminating current terrorists but the undesirable indirect effect of increasing ITO's recruitment rate [17]. All these flows are depicted in Figure 1.

As far as the authors know, there is little published in the scientific literature concerning how best to model ITO's recruiting practices and abilities. ${ }^{2}$ We imagine here that the undesirable indirect effects of what is perceived

that should be understood to be actions such as invading Afghanistan, using Predator drones with Hellfire missiles to assassinate Al-Qaeda operatives as in Yemen, or freezing assets of organizations with links to Al-Qaeda.

${ }^{2}$ Kaplan et al. [17] estimate recruitment, attack, death, and growth rates for a related discrete-time descriptive growth model for the evolution of the strength of terrorist organizations in the West Bank, which may or may not be similar to ITO in this regard. 


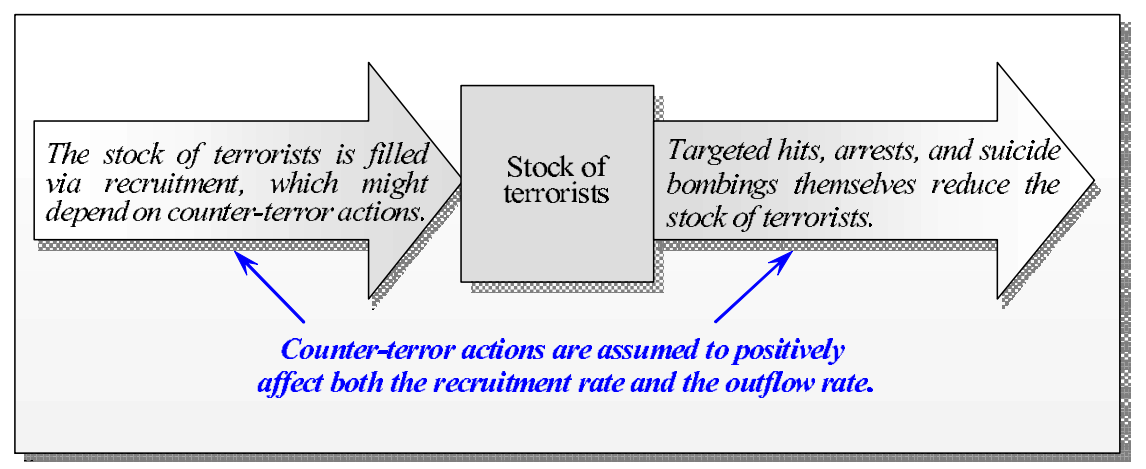

Figure 1: Flow chart of the "dynamics of terror"

as excessive and inappropriate terror control attacks increases more than proportionally with the intensity of those attacks. That is, we imagine that in the eyes of a potential terrorist recruit, some degree of counter-attacking is to be expected, but excessive levels stimulate sympathies with ITO. This over proportional increase in sympathy could arise not only from the sheer volume of attacks, but also because of heterogeneity in the "specificity" of attack opportunities. The less specific the attack, the more collateral damage that is caused to innocent people and, therefore, the rate of sympathy among the population is going to increase. Because the West prefers highspecificity attacks, these attacks are undertaken when possible.

A "high-specificity attack" as the term is used here would refer to an attack on people known to be ITO members who are guilty of specific past or planned attacks. Therefore, a high-specificity attack would not involve significant collateral damage to innocent civilians, mosques or other Holy sites, etc. and would minimize violation of Arab nation's sovereignty. (E.g., an ITO operative is arrested in a Western country in the course of planning an attack and with unambiguous physical artefacts proving that a terror attack was being prepared.) A "low-specificity attack" would be bombing a site occupied by both ITO personnel and innocent non-combatants. A historical example would be the Clinton Administration's launching cruise missiles against targets in Sudan and Afghanistan. A hypothetical example (that crosses a line not yet crossed) would be a cruise missile attack or other bombing of a mosque or shrine during Ramadan that killed many more bystanders than it did ITO operatives.

As the West expands its terror control efforts, it might be forced to resort to low-specificity tactics once it has exhausted the opportunities for highspecificity attacks. That could contribute to the adverse effect on ITO's recruitment rate increasing more than proportionally with the intensity of those attacks. 


\section{The Model}

\subsection{State Dynamics}

Translating the considerations presented in section 2 into equations the number of terrorists at time $t, x(t)$, evolves according to the equation

$$
\begin{aligned}
& \dot{x}(t)=f(x(t))-\mu w(t)-g(v(t)) w(t)-\phi v(t)+h(v(t)), x(0)>0, \\
& x(t) \geq 0 \quad \ldots \quad \text { number of terrorists at time } t \text {, relative to the ITO steady } \\
& \text { state population in "peacetime" (=state variable), } \\
& v(t) \geq 0 \quad \ldots \quad \text { intensity of the West's terror control activities at time } \\
& t \text {, relative to its maximum sustainable level (=control } \\
& \text { variable of "the West"), } \\
& w(t) \geq 0 \quad \ldots \quad \text { number of ITO attacks at time } t \text { (=control variable of } \\
& \text { ITO), } \\
& f(x(t)) \quad \ldots \quad \text { endogenous growth of ITO at time } t \text {, } \\
& \mu \geq 0 \quad \ldots \quad \text { average number of terrorists killed or arrested per attack, } \\
& g(v(t)) \quad \ldots \quad \text { number of terrorists lost per terror attack due to terror } \\
& \text { control efforts } v(t) \text {, } \\
& \phi \geq 0 \quad \ldots \quad \text { rate at which terror control operations would deplete } \\
& \text { ITO if the West is on full counter-offensive, } \\
& h(v(t)) \quad \ldots \quad \text { growth of ITO at time } t \text { due to hatred caused by collat- } \\
& \text { eral damage induced by (low-specificity) terror control } \\
& \text { activities of the West. }
\end{aligned}
$$

We suppose that during "peacetime" (when neither player is making attacks), ITO would grow to some maximum, "natural" size which we normalize to one without loss of generality. Accordingly a value of, e.g., $x(t)=0.5$ corresponds to a situation where the current size of ITO is half its "peacetime" level.

We have no data or experimental opportunities with which we might test and validate alternative functional forms for the model given by Equation (1). We proceed with simple linear and quadratic forms for the sake of transparency, tractability, and in recognition that the very structure of the model (e.g., reifying terrorist and terror control forces as single actors and tactics as single controls) implies that it will inevitably be highly stylized relative to the complexity of the true phenomena.

We assume that ITO (=number of terrorists $x(t)$ ) grows logistically in the absence of controls, i.e.,

$$
f(x(t))=\gamma(1-x(t)) x(t)
$$

where $\gamma$ denotes the endogenous growth rate. ${ }^{3}$ ITO's size declines propor-

\footnotetext{
${ }^{3}$ Note that the so-called "carrying capacity" corresponds to the steady state population in "peacetime" which is normalized to one.
} 
tionally to the number of attacks at time $t$ as embodied in the first outflow term $\mu w(t)$. The second outflow term originates from the fact that the West's control $(v(t))$ contributes positively to the probability of finding (and arresting) ITO operatives who knew somebody involved in an attack, i.e.,

$$
g(v(t))=\beta v(t) .
$$

The parameter $\beta$ in Equation 3 denotes the ratio of ITO operatives lost per successful attack when the West is on full counter-offensive $(v(t)=1)$ vs. none at all.

Moreover, the terror control activities $(v(t))$ reduce the number of terrorists directly, represented by the third outflow term $\phi v(t)$. That is, the West can attack terrorists, not only counter-attack when the terrorists strike. It is precisely that sort of unprovoked preemptive strike that might be most likely to fuel anger against the West. Consequently, it is plausible to assume that "inappropriate" terror control (seen from a non-West point of view) leads to an increase in the recruitment of new terrorists represented by the inflow term

$$
h(v(t))=\alpha v(t)^{2} .
$$

The parameter $\alpha$ denotes the growth rate of ITO due to hatred caused by collateral damage induced by the West's "low-specificity" terror control attacks. The terms $-\phi v(t)$ and $-\beta v(t) w(t)$ and the term defined by Equation 4 account for the two-edged effect of terror control activities discussed in section 2. This means that there may be a "narrow corridor" of suitable control measures - too little or too much may be suboptimal.

The overall direction of terror control policy is stable and transparent to all. If a country is attacked, it will counter-attack. That was the bedrock of "Mutual Assured Destruction" (MAD) doctrine during the Cold War and, indeed, in some sense is fundamental to the doctrine of essentially any country. Consequently, it is doubtful that Al-Qaeda expected that it could conduct something like the September $11^{\text {th }}$ attacks without eliciting a substantial response. So in some sense the West's behavior is predictable to ITO. ${ }^{4}$ Once it has been attacked, the West cannot unilaterally decide to stop fighting. For the sake of credibility (and deterrence) it has to stick to its "counter-strike strategy". This suggests using an open-loop information pattern for the modeled "game on terror", even though ITO has a higher degree of freedom than the West in varying the frequency and aggressiveness of its attack strategy.

Since it is not realistic to suppose that the West could never "learn" and modify its policy rule even in the long-run, we examine a finite time horizon problem. Inasmuch as the US is a key driver of the West's strategy vis à vis offensive terror control operations, one might think of this time horizon as

\footnotetext{
${ }^{4}$ The Terror War is assumed to be initiated by a September, $11^{\text {th }}$-like attack.
} 
akin to the US presidential election cycle (or even shorter periods of time). In 2004 the US re-elected George Bush as president, and he can reasonably be expected to continue the Terror War more or less along the lines he had for the previous three years. The US could instead have elected John Kerry, which might have led to some change in strategy for the US and for the West more broadly. So national elections can be thought of as opportunities for altering strategy, as the Spanish elections did after the Madrid bombing, but between elections one might expect the West's strategy to be fairly stable in the sense that ITO can take it as given when choosing its strategy.

\subsection{Objectives}

We presume that the West may have up to three policy goals and thus up to three components of its objective function. The West certainly wants to minimize the number of terrorist attacks $w(t)$, but it may also independently seek to minimize the number of terrorists (by minimizing $x(t)$ ). The principal reason the West might dislike there being a lot of terrorists is their potential to commit attacks, which would be captured in a $w(t)$ term in the objective. However, merely living under the threat of attack can be costly, even if there are not attacks, because of the cost of maintaining homeland security capacity, psychological stress, and activities (e.g., business investments) avoided because of the uncertainty created by an imminent threat.

The West also has an interest in minimizing the number of terror control strikes (by minimizing $v(t)$ ). One obvious reason is that terror control efforts cost money, just as does the exercise of almost any control policy. Decision-makers in optimal control formulations (with or without a game-theoretic component) are routinely described as trying to minimize a weighted sum of the magnitude of a problem $(x(t)$ and $w(t)$ in this case) and the costs of efforts intended to reduce that problem $(v(t)$ in this case).

With respect to the objective function we proceed with simple functional forms for the sake of transparency and tractability. In particular, we assume that the objective function components are linear in their respective arguments. Hence, for a finite time horizon $[0, T]$ and a positive discount rate $r$ the West's objective can be written as

$$
\max _{v(t)}\left\{-\int_{0}^{T} e^{-r t}\left\{c_{1} x(t)+c_{2} w(t)+c_{3} v(t)\right\} d t-e^{-r T} s x(T)\right\},
$$

where $s x(T)$ denotes the salvage value which is proportional to the stock of terrorists at the end of the time horizon.

Relative to the costs imposed by terror attacks, direct budgetary outlays on terror control attacks (as distinct from homeland security and the invasion of Iraq) are fairly modest. So if the West thought the only cost 
of employing $v(t)$ was budgetary or if the cost of intervention "didn't matter", because the Terror War has to be fought regardless of the efforts it takes, $v(t)$ would be a negligible part of the West's objective.

However, political stability in the Gulf region is of first-order importance to the strategic interests of all oil-importing countries. If overzealous terror control operations stirred up hostility to the West that led to an interruption of Persian Gulf oil shipments akin to the OPEC oil embargo of 1972 that could have ramifications for Western economies far larger than the direct budgetary costs of those terror control operations. Hence, from this larger politically oriented perspective, one could justify making $c_{3}$ an important component of the West's overall objective function. Hence, we explore the special case in which $c_{3}=0$ and the more general case in which it is positive.

ITO, on the other side, is interested in becoming strong and powerful (by increasing $x(t)$ ). Furthermore, it may value deaths of Westerners that are a direct consequence of its performing successful attacks (by increasing $w(t)$ ). Additionally (or alternatively), ITO might have political objectives aiming at inducing "excessive" counter-attacks by the West (elicit high values of $v(t)$ ) as an indirect way of stirring up anti-Western sentiments in the Middle East. E.g., these anti-Western moods could smooth the way for changes in local regimes. These considerations lead to the following objective function of ITO for a finite time horizon $[0, T]$ and a positive discount rate $r$ (where we assume that the objective function components are linear in their respective arguments):

$$
\max _{w(t)}\left\{\int_{0}^{T} e^{-r t}\left\{d_{1} x(t)+d_{2} w(t)+d_{3} v(t)\right\} d t+e^{-r T} \underline{s} x(T)\right\},
$$

where $\underline{s} x(T)$ denotes the salvage value.

Consequently, we investigate an asymmetric noncooperative open-loop differential game for a finite time horizon $[0, T]$ and a positive discount rate $r$ with the West optimally predetermining its strategy at time $t=0$. The West and ITO aim at satisfying Equations (5) and (6), respectively, subject to

$$
\begin{gathered}
\dot{x}(t)=\gamma(1-x(t)) x(t)-\mu w(t)-\beta v(t) w(t)-(\phi-\alpha v(t)) v(t), x(0)>0, \\
x(t), v(t), w(t) \geq 0 .
\end{gathered}
$$

\subsection{Solution Concept}

The final component of the model specification is the choice of the solution concept (given an open-loop information pattern), which governs how the 
"game" will be played. We adapt some familiar concepts slightly to fit the present context.

We have already alluded to the first key component of the solution concept. The West announces its policy ahead of time and locks into that policy for the duration of the (finite-horizon) game. Note, however, what is announced. The West does not commit to a particular intensity of attacks $(v(t))$ irrespective of ITO's actions, $w(t)$. Rather, the West announces a set of contingencies. It says, in effect, "If you - ITO - do not attack us, we will not attack you. ${ }^{5}$ However, if you attack us, we will strike back. In particular, if you attack our interests abroad (e.g., bombing embassies) you can expect a limited military response. But if you kill our civilians on our soil, we are willing to commit ground troops." So what the West announces is $v(t)$ as a function of $w(t)$. ITO takes that policy as given, and chooses its own actions, represented by $w(t)$, accordingly.

Hence, our solution concept is related to incentive strategies that assume that each player has knowledge of each other's actions, and employs strategies making use of this information. Essentially, in incentive problems it is assumed that the strategy of one of the decision-makers is a function of the decisions of the other players. There is, however, a notable difference between the War on Terror and standard contexts to which incentive equilibrium concepts have been applied in the past, ${ }^{6}$ namely that the West has at best very imperfect understanding of ITO's objectives. One hears claims varying from standard political agendas (get US troops out of the Middle East or overthrow secular pro-Western Arab regimes) to objectives that are "rational" given certain (extreme) religious beliefs (e.g., the heavenly rewards accorded to martyrs) to statements that Al-Qaeda's actions are driven by irrational hatred and are not a means to any particular end.

Ignorance of the opponent's objective has a very practical consequence in the context of dynamic games. If the West does not understand ITO's objective, it cannot know how valuable the stock of terrorists is to ITO. I.e., the West can observe ITO's actions $(w(t))$, but it cannot observe ITO's motives and, hence, does not know the shadow price ITO places on the state variable, $x(t)$.

We presume that the West tries to be as rational as it can be in the face of this information deficit in the sense of optimizing over all factors that it knows about, including its own shadow-price on an additional terrorist. That is, we do not relegate the West to behaving myopically. Rather, we

\footnotetext{
${ }^{5}$ Any time delay is neglected since the ITO attacks are (assumed to be) observed in real time, and the West tries to react to these attacks as soon as possible. ${ }^{6}$ Incentive problems are usually treated in the context of cooperative symmetric games. For an intuitive explanation, the mathematical formulation and interesting applications of incentive equilibria consult, e.g., the work of Ehtamo and Hämäläinen $[8,9,10]$.
} 
proceed as if the West were computing a standard incentive equilibrium, but simply omit ITO's shadow price from the West's calculations.

We also omit the West's shadow-price from ITO's optimization, but for an entirely different reason. Presumably ITO can observe the objectives and values of the West; democratic societies are rather open in this regard. So ITO may have fine information about the West's shadow prices. However, ITO cannot usefully manipulate those shadow prices.

Before launching a terror campaign, any given international terrorist organization is essentially a non-entity in the strategic planning and political processes of a Western country. For the US for example, defense policy before September $11^{\text {th }}$ was much more influenced by the Cold War, the Vietnam War, and the Gulf War than it was by anything Al-Qaeda might do or say. It was predicated on a wide range of threat scenarios, not just large-scale terrorist attacks on the US homeland. (Indeed, that particular threat scenario received relatively little attention before September $11^{\text {th }}$ and so did not figure prominently in defense policy planning.) This is very different than strategic modeling of interaction among peers, such as duopolies in business or the West and Soviet bloc in the Cold War. Whatever the West was doing before the game begins did not in any meaningful way revolve around ITO, and after the game begins, the West plays out the strategy to which it has pre-committed. Hence, ITO simply receives the West's policy as given, and cannot influence the shape of that policy by its threats or actions.

Hence, a suitable game concept is an incentive Stackelberg game with the West acting as the leader and ITO as the follower. ${ }^{7}$ In such setting the leader can "force" the follower to play his global optimum by using a strategy that depends on the follower's action (provided the follower plays open-loop).

\section{Analyzing the Terror War}

As outlined above, the West determines its strategy $v(t)$ for any potential frequency with which terrorist attacks could be executed (embodied in the

\footnotetext{
${ }^{7}$ The "incentive Stackelberg equilibrium solution concept" used in this paper mainly differs from the well-known concept of an open-loop, finite time horizon Stackelberg game (see, e.g., Dockner et al. [7], or Başar and Olsder [1]) with respect to the presumed behavior of the West. Here the West does not "announce" the way in which it will perform its terror control activities (to ITO), it predetermines its strategy responding to any (possible) number of terror attacks (as opposed to the number of attacks presumably being most favorable for ITO as a rational decision-maker). Hence, the deviation from the "classical" Stackelberg approach is caused by the West's ignorance of the principles or presence of the "rationality" of the ITO player and by ITO's limited ability to influence the West's policy before the beginning of the game.
} 
variable $w(t))$ yielding $v(w(t))$. Certainly, it is plausible to assume that the West's terror control policy is performed "in the best possible way", i.e. by maximizing the objective function (5), yielding $v^{\star}(w(t)){ }^{8}$

Therefore, the West determines the optimal terror control activities $v^{*}(w(t))$ by solving an optimal control problem with respect to $v(t)$. Omitting the explicit notion of time from now on, the mathematical analysis of the Terror War starts at the current value Hamiltonian $\mathcal{H}_{1}$ for the West,

$$
\mathcal{H}_{1}=-c_{1} x-c_{2} w-c_{3} v+\pi_{1}(\gamma(1-x) x-\mu w-\beta v w-(\phi-\alpha v) v) .
$$

The West's shadow price $\pi_{1}$ is always negative along the optimal path since $\frac{\partial \mathcal{H}_{1}}{\partial x}<0$ (see Léonard [19]), i.e., ITO adding one more operative is always damaging to the West. Pontryagin's maximum principle (for the general theory see, e.g., Başar and Olsder [1], Dockner et al. [7], Feichtinger and Hartl [11], Léonard and Long [20]) determines the evolution of the West's shadow price of an additional terrorist:

$$
\dot{\pi}_{1}=(r-\gamma+2 \gamma x) \pi_{1}+c_{1}, \pi_{1}(T)=-s .
$$

Consequently, the damage implied by having one more terrorist (seen from the West's point of view) increases due to a decreasing per capita cost associated with the mere existence of ITO $\left(c_{1}\right)$. Then the maximizing condition for the intensity of the West's terror control interventions $(v)$ is given by

$$
\frac{\partial \mathcal{H}_{1}}{\partial v}=0 \Leftrightarrow-c_{3}+\pi_{1}(-\beta w-\phi+2 \alpha v)=0 .
$$

We assume that terrorist organizations know what the West will do if it is attacked (according to the policy rule implicitly determined by Equation 11). Therefore, the terrorists plug the West's strategy $v^{\star}:=v^{\star}(w)$ into their objective function (6), and solve an optimal control problem with respect to $w$. Thus, the Hamiltonian $\mathcal{H}_{2}$ for ITO can be determined by

$$
\mathcal{H}_{2}=d_{1} x+d_{2} w+d_{3} v^{\star}+\pi_{2}\left(\gamma(1-x) x-\mu w-\beta v^{\star} w-\left(\phi-\alpha v^{*}\right) v^{\star}\right),
$$

where $\pi_{2}$ is always positive along the optimal path since $\frac{\partial \mathcal{H}_{2}}{\partial x}>0$ (see Léonard [19]), i.e., one more ITO operative is always a benefit for the terrorists. Since the West locks in its policy before the dynamic part of the game commences, and ITO cannot influence the West's policies before launching its terror war, at this point the analysis becomes unilateral dynamic

${ }^{8}$ Considering the state and control constraints $(x, v, w \geq 0)$ we perform the "direct adjoining approach" [11, pp.164] which is not explicitly described in this section. The results derived here contain, however, the analysis at the border of the admissible regions as well. 
optimization without factoring in the opposing player's shadow price. The terrorists' imputed value of an additional terrorist evolves according to

$$
\dot{\pi}_{2}=(r-\gamma+2 \gamma x) \pi_{2}-d_{1}, \pi_{2}(T)=\underline{s} .
$$

The maximizing condition for the number of ITO attacks $(w)$ is determined by

$$
\frac{\partial \mathcal{H}_{2}}{\partial w}=0 \Leftrightarrow d_{2}+d_{3} \frac{\partial v^{\star}}{\partial w}-\pi_{2}\left(\mu+\beta w \frac{\partial v^{\star}}{\partial w}+\beta v^{\star}\right)=0 .
$$

The following proposition provides essential information about the interior solutions. Note that even though we normalize $v^{\star}=1$ to stand for the maximum long-run sustainable intensity of terror control activities, brief periods of "extra-intensity" $\left(v^{*}>1\right)$ are possible due to the nature and speed of modern armed conflict.

Proposition 4.1. If $\left|\pi_{1}\right|>c_{3} /(\beta w+\phi)$ and $\pi_{2}<\left(2 \alpha d_{2}+\beta d_{3}\right) /(2 \alpha \mu+$ $\beta \phi)$ hold, the following pair of strategies constitutes an interior noncooperative incentive equilibrium solution at $\left(v^{*}(w), w^{*}\right)$ :

$$
\begin{gathered}
v^{\star}(w)=\frac{1}{2 \alpha}\left(\frac{c_{3}}{\pi_{1}}+\beta w+\phi\right)>0, \\
w^{\star}=\frac{1}{\beta^{2}}\left(\frac{2 \alpha d_{2}+\beta d_{3}}{\pi_{2}}-2 \alpha \mu-\beta \phi\right)>0 .
\end{gathered}
$$

The intensity of the West's (interior) terror control interventions evolves nearly proportional to the number of terror attacks, $w^{\star}$, and almost indirectly proportional to the West's shadow price of an additional terrorist, $\pi_{1}<0$. Therefore, the West's policy also depends on the current stock of terrorists. The West's incentive Stackelberg strategy does not, however, depend on the initial state of the game. Hence, it will be optimal for the Stackelberg leader to use this strategy from any initial state and time.

Moreover, Equation 15 tells us that the intensity of terror control interventions is low when the cost of intervention, $c_{3}$, is high (since $\pi_{1}$ is negative). On the contrary, if the cost of intervention "doesn't matter", because the Terror War has to be fought regardless of the efforts it takes $\left(c_{3}=0\right)$, the intensity of terror control interventions is a linear (affine) function of the number of terrorist attacks. In this case we can guarantee that $v^{\star}(w)$ is always positive along the optimal path, since $w \geq 0$. (See Equation 8.) Proposition 4.1 states that $v^{\star}>0$, as long as $c_{3} /\left|\pi_{1}\right|<(\beta w+\phi)$. This condition is computed by adding a Lagrangian-type expression to the West's Hamiltonian. If $c_{3} /\left|\pi_{1}\right| \geq(\beta w+\phi)$, the necessary conditions for interior solutions are not satisfied and we observe solutions at the border of the 
admissible region, because the respective Lagrangian multiplier is positive, forcing the intensity of anti-terror interventions to be zero, i.e., $v^{\star}(w)=0$.

For ITO the "optimal" number of attacks is determined by Equation 16. Attack rates are implicitly driven by the stock of terrorists (via its "per capita value" $\pi_{2}$ ). This is important, since the number of attacks $\left(w^{\star}\right)$ exceeds zero only if the imputed value $\left(\pi_{2}\right)$ of an additional terrorist (seen from the terrorists' point of view) stays below a certain threshold level determined by $\pi_{2}<\left(2 \alpha d_{2}+\beta d_{3}\right) /(2 \alpha \mu+\beta \phi) .{ }^{9}$ (See Proposition 4.1.) Above this threshold level, a terrorist would be regarded as "too valuable" for the terrorist organization to risk losing the terrorist during an attack. Thus according to Equation 16, one way the West could reduce the number of ITO activities $\left(w^{\star}\right)$ is by bringing ITO's valuation of its stock of terrorists up to a high level (especially toward the end of the game). This policy would correspond to altering the parameter $\underline{s}$ (if possible) as outlined in the following Proposition.

Proposition 4.2. If ITO's salvage value coefficient satisfies the condition $\underline{s} \geq\left(2 \alpha d_{2}+\beta d_{3}\right) /(2 \alpha \mu+\beta \phi)$, the West can wipe out successively the number of terror attacks by making them less and less attractive for ITO, until the "war is over" at time $T\left(\rightarrow w^{\star}(T)=0\right)$. If additionally $s \leq c_{2} / \phi$ holds for the West's salvage value coefficient, then the West ceases fire as well and its intensity of terror control activities is equal to zero $\left(\rightarrow v^{\star}(T)=0\right)$. That is that the Terror War truly comes to an end at the end of the (finite) time horizon.

We are most interested in the finite time horizon case for reasons discussed above, but it is not entirely clear what that time horizon should be. An infinite time horizon is in some respects the limiting case as the finite time horizon gets large, so the infinite time horizon case is of interest to the extent that it may in some sense "bound" the behavior of the finite time horizon case.

For $T=\infty$ the Terror War can approach the uniquely determined "long run equilibrium state" $\hat{x}_{1}$ or $\hat{x}_{2}$ given by Equation 17 or by Equation 18, respectively. ${ }^{10}$ Denoting the two players' costates in equilibrium $\hat{x}_{i}(i=$

\footnotetext{
${ }^{9}$ The condition $\pi_{2}<\left(2 \alpha d_{2}+\beta d_{3}\right) /(2 \alpha \mu+\beta \phi)$ is computed by adding a Lagrangian-type expression to ITO's Hamiltonian. If $\pi_{2} \geq\left(2 \alpha d_{2}+\beta d_{3}\right) /(2 \alpha \mu+$ $\beta \phi)$ the Lagrangian multiplier is positive, forcing $w^{\star}$ to be zero.

${ }^{10}$ Note that $\hat{x}_{1}$ and $\hat{x}_{2}$ (as implicitly determined by Equations 17 and 18) never simultaneously satisfy the state constraint $x(t) \geq 0$.
} 
$1,2)$ with $\hat{\pi}_{1 i}$ and $\hat{\pi}_{2 i}$, respectively, we get

$$
\hat{X}=\left(\begin{array}{c}
\hat{x}_{1} \\
\hat{\pi}_{11} \\
\hat{\pi}_{21}
\end{array}\right)=\left(\begin{array}{c}
\frac{\gamma\left(r \beta^{2}-\Phi\right)+(r-\gamma) \Xi}{2 \gamma\left(r \beta^{2}-\Xi\right)} \\
-\frac{c_{1}\left(r \beta^{2}-\Xi\right)}{r^{2} \beta^{2}-\gamma \Phi} \\
\frac{d_{1}\left(r \beta^{2}-\Xi\right)}{r^{2} \beta^{2}-\gamma \Phi}
\end{array}\right)
$$

and

$$
\hat{Y}=\left(\begin{array}{c}
\hat{x}_{2} \\
\hat{\pi}_{12} \\
\hat{\pi}_{22}
\end{array}\right)=\left(\begin{array}{c}
\frac{\gamma\left(r \beta^{2}-\Phi\right)-(r-\gamma) \Xi}{2 \gamma\left(r \beta^{2}+\Xi\right)} \\
-\frac{c_{1}\left(r \beta^{2}+\Xi\right)}{r^{2} \beta^{2}-\gamma \Phi} \\
\frac{d_{1}\left(r \beta^{2} \Xi\right)}{r^{2} \beta^{2}-\gamma \Phi}
\end{array}\right)
$$

where

$$
\begin{gathered}
\Phi:=\beta^{2} \gamma+4 \mu(\alpha \mu+\beta \phi)>0 \\
\Psi:=\alpha \beta^{2} d_{1}^{2}+\gamma\left(2 \alpha d_{2}+\beta d_{3}\right)^{2}>0 \\
\Xi:=\frac{1}{\alpha c_{1} d_{1}^{2}} \sqrt{\alpha d_{1}^{2}\left(r^{2} \alpha \beta^{4} c_{1}^{2} d_{1}^{2}-\left(r^{2} \beta^{2}-\gamma \Phi\right)\left(c_{1}^{2} \Psi-\beta^{2} \gamma c_{3}^{2} d_{1}^{2}\right)\right) .}
\end{gathered}
$$

\section{Illustrating the Optimal Deterrence Policy}

It is difficult to parameterize this model because of lack of data and because of its high-level of abstraction. Appendix A.1 provides rationales that we hope yield parameter values that are of the right order of magnitudes (given by Table 1), and we vary certain parameters to explore sensitivity of the conclusions with respect to those values.

We discuss the incentive Stackelberg solutions for a finite time horizon in section 5.1. In particular, we consider the Terror War in the absence of political objectives of ITO $\left(d_{3}=0\right)$ and in the absence of an explicit "interest" of the West in the cost associated with terror control interventions $\left(c_{3}=0\right)$. In section 5.2 we describe the results of the game on terror for the infinite time horizon case and list the outcomes of static comparative (sensitivity) analysis. Time horizons on the order of $2-4$ years probably make the most sense, but we certainly do not know the proper value of $T$ with any specificity. Hence, we do the finite time horizon analysis with a very conservative (small) value of $T=0.5$ which, together with the infinite time horizon, brackets any plausible value of $T$ that might be of interest. Finally, section 5.3 briefly considers the implications of including parameters $d_{3}$ and $c_{3}$ in the analysis, which reflects political ambitions of ITO. 


\subsection{Finite Horizon Incentive Stackelberg Strategies for $c_{3}=0$}

When the cost of terror control operations is negligible compared to the cost of terror and hence is excluded from the West's objective function $\left(c_{3}=0\right)$, the West's shadow price of an additional terrorist does not enter the analysis. All that counts is the terrorist organization's shadow price of an additional terrorist $\left(\pi_{2}\right)$ and $\pi_{2}$ 's value at the end of the Terror War $(\underline{s})$. (See Equation 15.) In particular, if $c_{3}=0$, the intensity of terror control operations is governed by

$$
v^{\star}(w)=\frac{1}{2 \alpha}(\beta w+\phi) .
$$

This can be interpreted as saying that the size of ITO becomes irrelevant for determining the terror control activity and the West responds to the number of attacks only. In particular,

Proposition 5.1. If the cost of terror control activities is irrelevant for the West, the intensity of its interventions is proportional to how effective terror control operations are relative to their adverse effect on terrorists recruitment $(\alpha)$, where the effectiveness includes both general effects ( $\phi)$ and the losses stimulated by responding to specific terror attacks ( $\beta w)$. Moreover, the intensity of terror control interventions $v^{\star}(w)$ is a linear (affine) function of the number of attacks $w$.

Accordingly, $w^{\star}$ and $v^{\star}$ evolve "hand in hand" and not "delayed" or antagonistically (where highly intensive terror control actions successfully suppress terror attacks). This "hand in hand"-type behavior is caused by the fact that the West's policy rule immediately responds to changes in the number of terrorist attacks leaving aside the current size of ITO as a future source of attacks. Proposition 4.2 stated that the Terror War ends if ITO's value of having an additional terrorist at the end of the time horizon exceeds a certain threshold level. For the base case parameter set this threshold level is given by $\underline{s} \geq\left(2 \alpha d_{2}+\beta d_{3}\right) /(2 \alpha \mu+\beta \phi)=14.1176$.

Figure 2 illustrates for base case parameter values the influence of increasing how much ITO values having terrorists alive at the end of the time horizon $(T)$ by varying parameter $\underline{s}$ around $\pi_{2}$ 's equilibrium level. Figure 3 does the same when ITO values more highly maintaining a stock of terrorists throughout the entire period of interaction (specifically, when $d_{1}$ increases from 1 to 20). In both cases we start with a stock of terrorists well above its equilibrium value.

What is a reasonable value for parameter $\underline{s}$ ? Since the salvage value is defined by $\underline{s} x(T)=\pi_{2}(T) x(T)$, we might use as a "benchmark" a value near the long-run equilibrium value of ITO's relative value of an additional terrorist, i.e. $\underline{s} \cong 7.04477$. Since by definition a finite time horizon implies 
Table 1: Base case parameter values

Interpretation of the parameter

value

$\gamma \quad$ Endogenous growth rate of terrorist organization

$\mu \quad$ Average number of terrorists killed or arrested

$\alpha \quad$ Growth rate of terrorist organization due to hatred caused by collateral damage induced by the West's terror control attacks

$\beta \quad$ Ratio of ITO operatives lost per successful attack when the West is on full counter-offensive vs. none at all

$\phi \quad$ Rate at which terror control would deplete terrorists for $v=1$

$r \quad$ Discount rate

$c_{1} \quad$ Relative cost to the West of a stock of terrorists

$c_{2} \quad$ Relative cost to the West of terrorist attacks

$c_{3}$ Relative cost to the West of conducting terror control operations

$s \quad$ Relative cost to the West of a stock of terrorists at time $T$

$d_{1}$ Relative value to ITO of maintaining a stock of terrorists

$d_{2}$ Relative value to ITO of attacking Western targets 20

$d_{3}$ Relative value to ITO of eliciting overzealous control oper- $\quad 0$ ations

$s \quad$ Relative value to ITO of maintaining $x$ at the time the war $\quad 6$ ends

some present orientation, we round that value down a bit, specifically to $\underline{s}=6$. As foils we also explore values half as large $(\underline{s}=3)$ and slightly above the threshold $(\underline{s}=15)$. As depicted by Figure 2 , for $\underline{s}=6$ ITO initially exploits its "excess" stock of terrorists by launching the terror war quite aggressively, and the West responds in kind with aggressive counter terror operations. This high intensity of conflict attrites ITO's stock of terrorists down to slightly below its peacetime levels by $T=0.5$, by which time terror and counter-terror operations are pursued at about half their original intensity. (That stock is still roughly twice as large as the long-run equilibrium level obtained if the Terror War is pursued for an infinite time horizon.)

If the imputed value of an additional ITO operative at the end of war is larger than the long-run equilibrium level $(\underline{s}=15$, dashed lines in Figure 

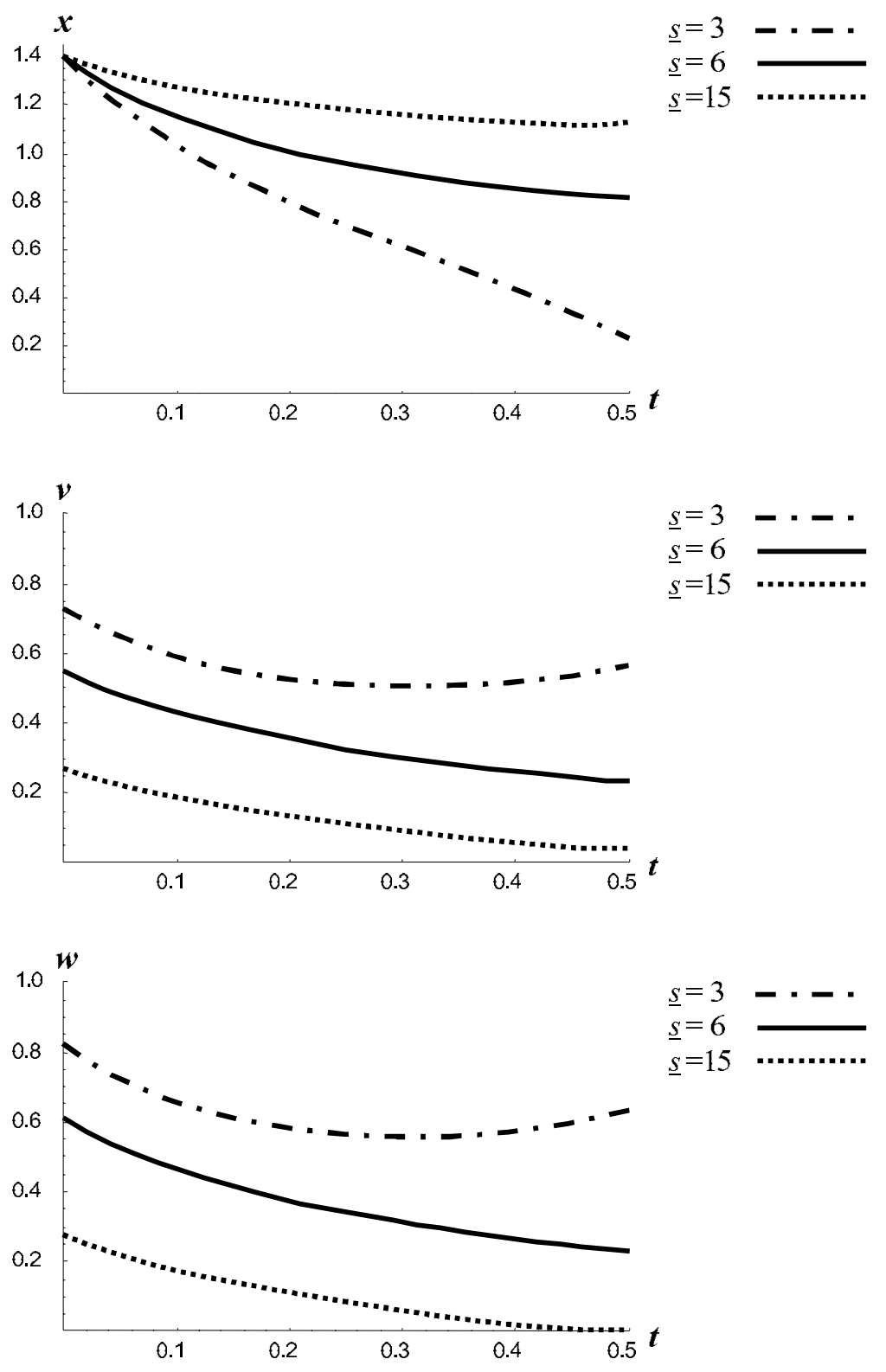

Figure 2: Noncooperative incentive equilibrium paths for the size of ITO $(x)$, the intensity of terror control measures $(v)$, and the number of attacks $(w)$ for the base case parameter set (see Table 1) and different values of $\underline{s}$. 

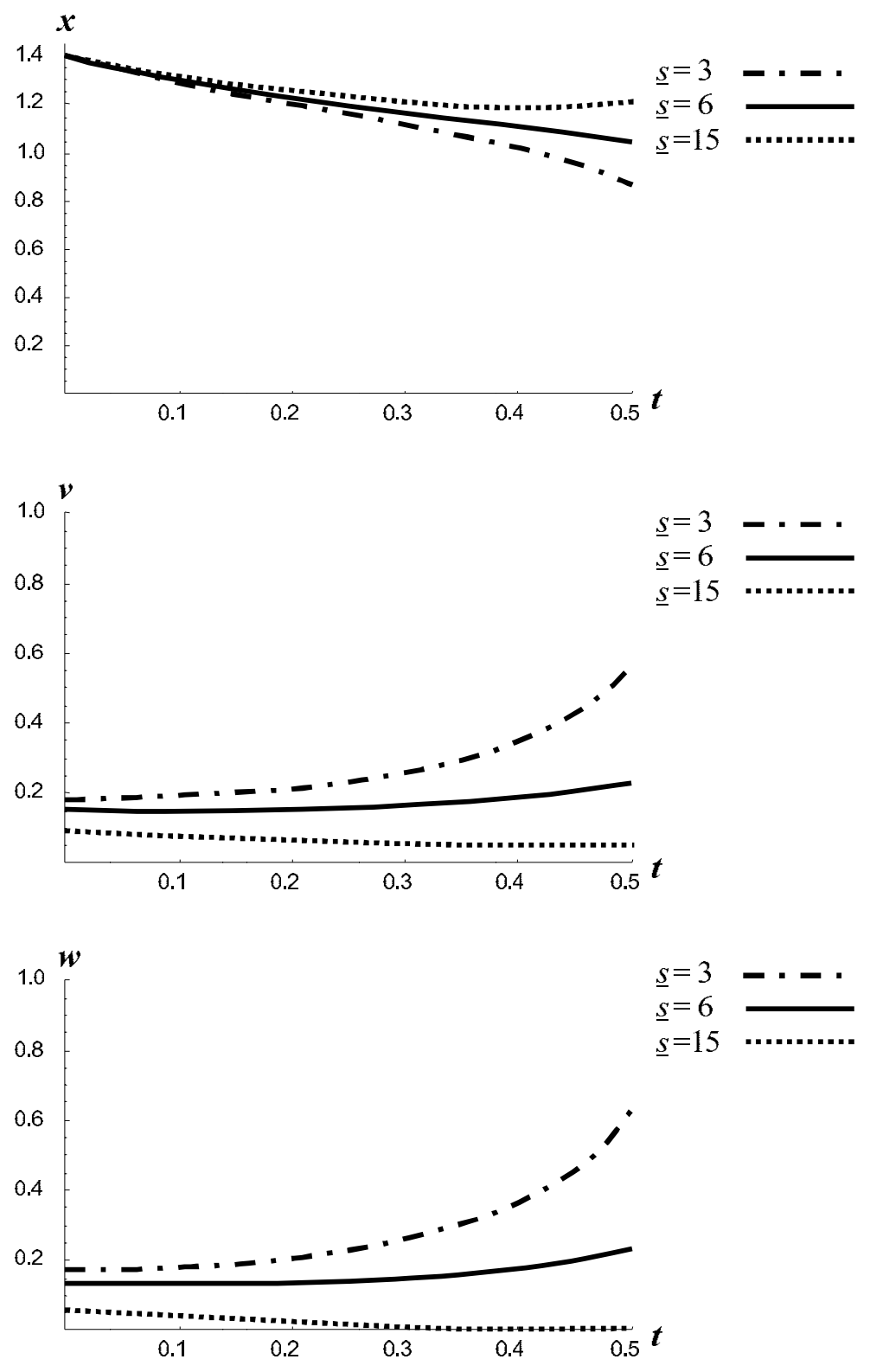

Figure 3: Noncooperative incentive equilibrium paths for the size of ITO $(x)$, the intensity of terror control measures $(v)$, and the number of attacks $(w)$ for the base case parameter set (see Table 1$), d_{1}=20$ and different values of $\underline{s}$. 
2), ITO (and hence the West too) is much less aggressive, and the initial excess in the stock of terrorists is preserved at least partially through the end of the time horizon. Indeed, as per Proposition 4.2, terrorist attacks cease towards the end of the time horizon, i.e., $w^{\star}(T=0.5)=0$.

Decreasing $\underline{s}$ has the opposite effect. Figure 2 shows that the stock of terrorists declines drastically towards the end of the time horizon for $\underline{s}=3$ (and the base case parameter values). If ITO does not value having many terrorists around, either during the time horizon (smallish $d_{1}$ ) or at its end (small $\underline{s}$ ), then it will commit them aggressively to suicide operations (large $w)$. By Equation 22 that in turn stimulates aggressive counter-terror efforts (large $v$ ).

So as $\underline{s}$ increases, ITO "trades" off numbers of current attacks for increases in its terminal size. One might expect similar effects from increasing parameter $d_{1}$, which denotes the relative value to ITO of maintaining a stock of terrorists. Furthermore, increasing $d_{1}$, ceteris paribus, is likely to reduce the intensity of the "substitution process" described above. These effects are indicated by comparing Figure $2\left(d_{1}=1\right)$ and Figure 3 $\left(d_{1}=20\right)$. As Figure 3 shows, the absolute magnitude of attacks declines as $d_{1}$ increases, ceteris paribus.

To summarize these insights, first, the ratio $d_{1} / d_{2}$ determines the structure of the trade-off between present and future killing capacity. Second, the absolute sizes of $d_{1}$ and $d_{2}$ determine the extents of these capacities. Third, the smaller/larger $d_{1}$ is, the more/less the size of $\underline{s}$ matters.

So far the analysis presumed a particular initial size of ITO. We next consider altering the initial values $x_{0}$. For this purpose Figure 4 depicts the dynamics of the canonical system in the state-costate-space (determined by Equations 7 and 13) for two terminal values $\underline{s}$ chosen above and below the long-run equilibrium level (i.e., for $\underline{s}=6$ and $\underline{s}=15$ ).

For base case parameter values and different values of $x_{0}$ Figures 4, 5, and 6 depict multiple trajectories where each one is optimal for a different length of the time horizon $T$.

As shown by Figure 4, if the size of the terrorist organization is initially larger than in peacetime $\left(x_{0}>1\right)$, the shadow price of an additional terrorist $\left(\pi_{2}\right)$ monotonously increases as the number of terrorists $(x)$ declines. This corresponds to a monotonous decline in the number of attacks (depicted by Figure 5) and, consequently, to a reduction of terror control interventions (shown by Figure 6).

If the size of the terrorist organization is initially smaller than in peacetime $\left(x_{0}<1\right)$ the size of ITO does not always evolve monotonically over time (see Figures 4-6). The number of terrorists can first decrease then increase (large $\underline{s}$ and $x_{0}>\hat{x}_{1}$ ) or first increase and then decrease (small $\underline{s}$ and $\left.x_{0}<\hat{x}_{1}\right)$. As the time horizon tends to infinity, the system dynamics follow the saddle path (represented by the bold arrow) approaching the 

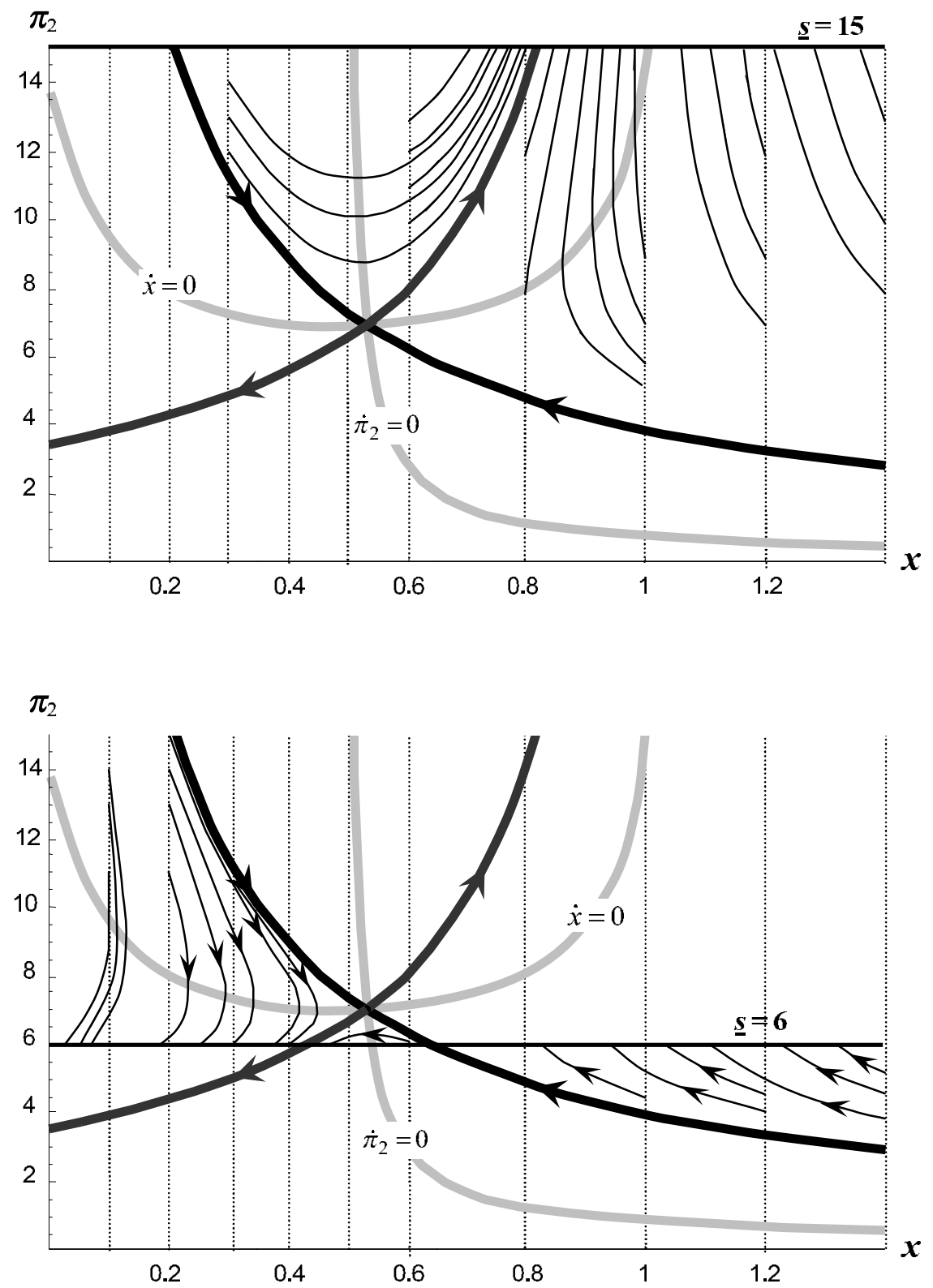

Figure 4: Phase plot in the state-costate space for the base case parameter values (see Table 1); Upper graphic for $\underline{S}(x(T))=15 x(T)$ and lower graphic for $\underline{S}(x(T))=6 x(T)$. 

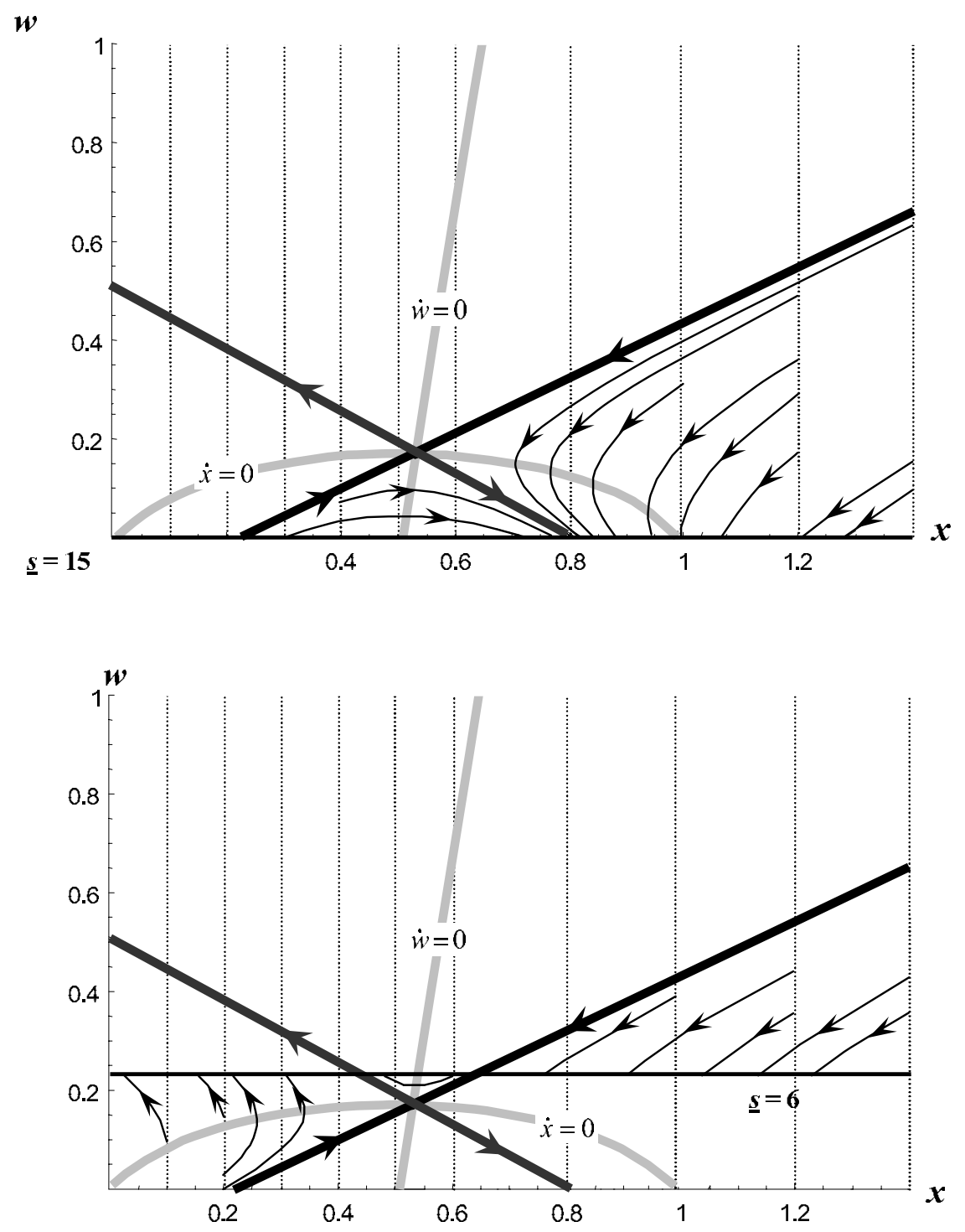

Figure 5: Phase plot in the state-control space for the base case parameter values (see Table 1); Upper graphic for $\underline{S}(x(T))=15 x(T)$ and lower graphic for $\underline{S}(x(T))=6 x(T)$.

long-run equilibrium stock of terrorists $\left(\hat{x}_{1}\right)$. For shorter time horizons, the optimal path takes the "faster" path farther away from the saddle-path.

From Figure 5 we derive that if $\underline{s}$ is close to $\hat{\pi}_{2}$, then the number of terror attacks $w$ is nearly a linear function of the size of the terrorist organization 

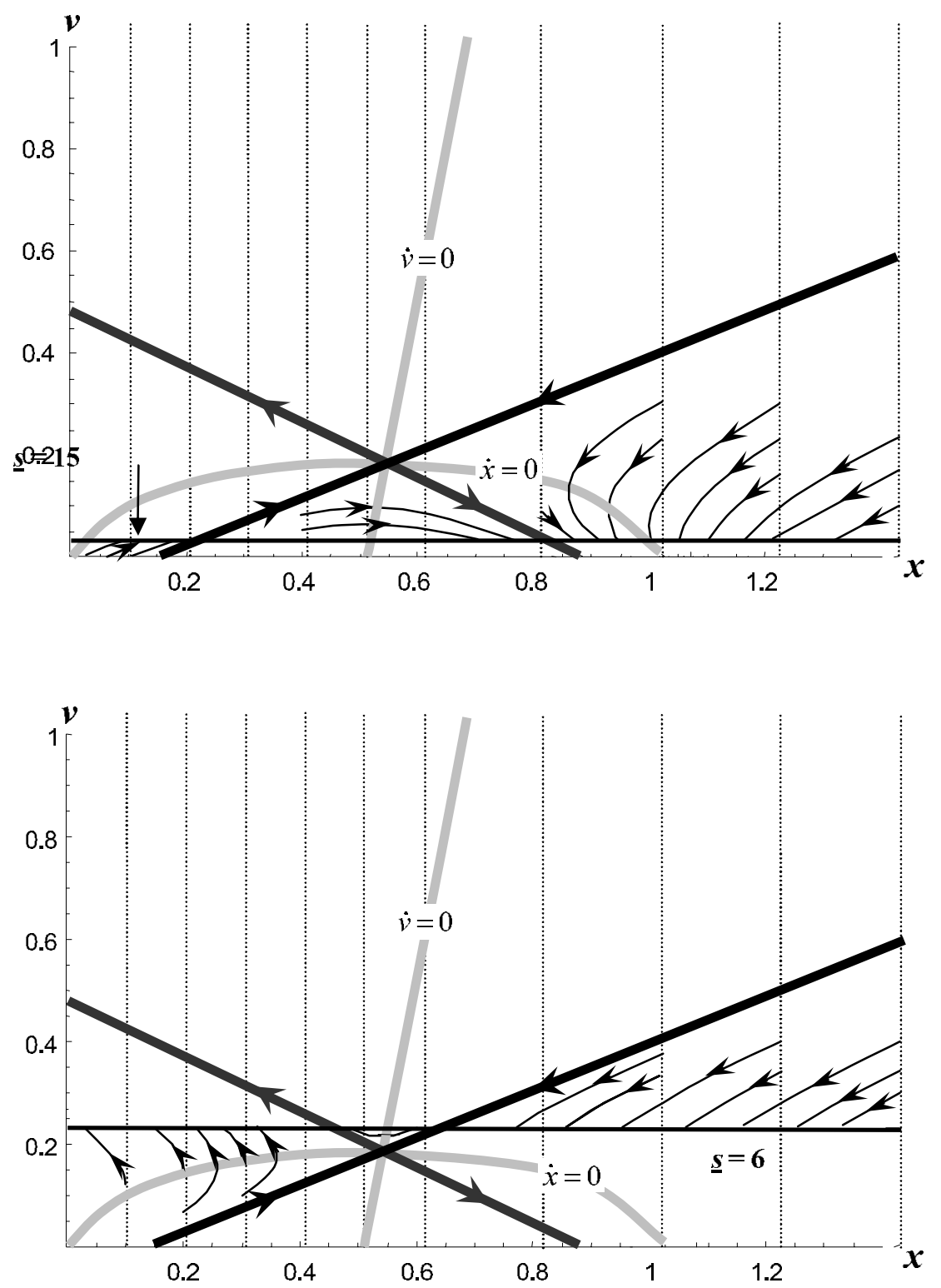

Figure 6: Phase plot in the state-control space for the base case parameter values (see Table 1); Upper graphic for $\underline{S}(x(T))=15 x(T)$ and lower graphic for $\underline{S}(x(T))=6 x(T))$. 
$x$, because the stable two-dimensional saddle-point manifold is (almost) linear. This "linear response" (Equation 22) to the frequency of terror attacks seems to quickly squeeze the growth and size of ITO $x$ (as depicted by Figure 6) as well as the number of attacks. However, in fact it is the reduction in $v$ per se that reduces the growth of $x$ (and consequently the level of $x$ and $w)$.

Static comparative analysis providing a brief discussion of the system behavior along the saddle-point manifold is discussed in the next section (to contrast with the results of the "short-run analysis" for the finite time horizon game).

\subsection{Infinite Horizon System Behavior for $c_{3}=0$}

Qualitatively the basic behavior of the system is rather straightforward when $T=\infty$. In the long run, the stock of terrorists will converge to a positive number smaller than the peacetime steady state size. (See Equation 19/20) War-time operations of both ITO and the West erode the stock of terrorists relative to peacetime levels, but since ITO controls the tempo of conflict, it does not pursue operations in a manner that leads to its own eradication.

One can think of this as vaguely akin to the Vietcong's strategy in Vietnam. There was little possibility of truly destroying the United States. Indeed, there were essentially no attacks on the US Mainland during the Vietnam War. So the best the Vietcong could do was to stay in the field fighting at the maximum intensity they could sustain, while using the ability of irregular forces to disappear into the jungles to prevent their forces from ever truly being eradicated.

This insight implies that in the long run the West has no way to bring the war to a close. Its optimal strategy is essentially reactive, with ITO controlling the tempo. However, the West may be able to manipulate certain parameter values as well as its current terror control operations $(v)$, so we explore some parametric sensitivity analysis.

The first set of results of the static comparative analysis is not surprising. The ratio of ITO operatives lost per successful attack when the West is on full counter-offensive vs. none at all $(\beta)$ and the rate at which terror control operations would deplete ITO operatives for $v=1(\phi)$ both calibrate the efficiency of terror control interventions. The more efficient terror control activities are (i.e., the larger parameters $\beta$ and $\phi$ are) the fewer terror attacks there will be (though there will be marginally more terror control operations).

Let us next have a look at the sensitivity results for some other parameters. Consider first parameter $\alpha$, which describes the extent to which terror control operations stimulate recruitment of terrorists. Changes in $\alpha$ have minimal effect on the stock of terrorists for the infinite time horizon case. 


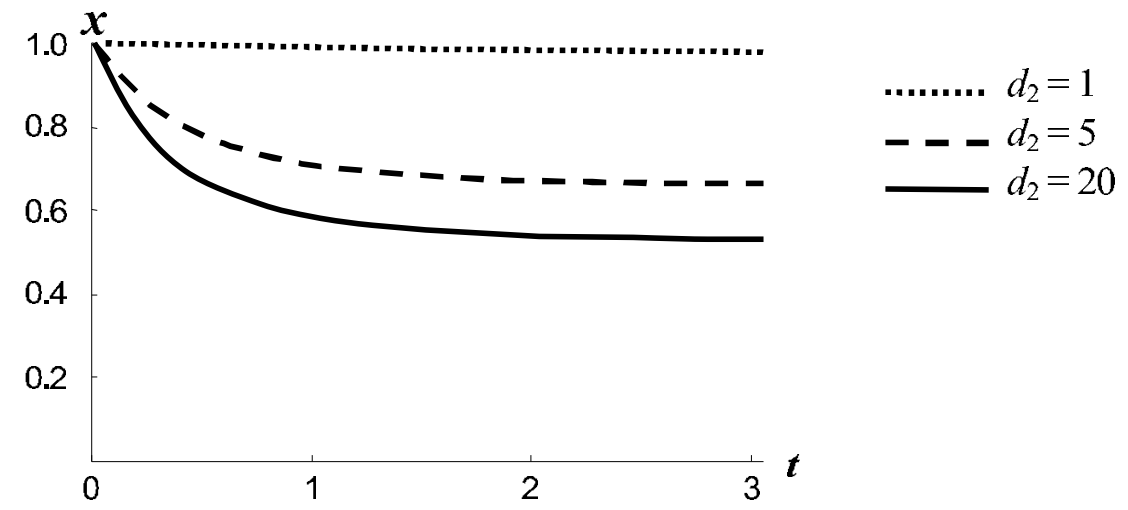

Figure 7: Incentive equilibrium paths for the strength of ITO $(x)$ for the base case parameter values and but for different values of the relative importance of bringing threat to the west $d_{2} ; T=\infty$ and $\underline{S}(x(T))=\underline{s} x(T)=\pi_{2}^{\star}(T) x(T)$ as a function of $d_{2}$. Solid line indicates the base case scenario.

However, a larger $\alpha$ makes it "more attractive" for terrorists to perform attacks ( $w$ high) and less attractive for the West to suppress terror over time. Conversely, if the West could somehow reduce $\alpha$, that would free it to pursue more aggressive terror control operations (raise $v$ ). ITO would respond in ways that protected its terror stock, but that means sharply curtailing the number of terror attacks, which is precisely one of the West's principal objectives.

Similar comments pertain to $\gamma$, which governs ITO's rate of recruiting in peacetime and, more generally, recruiting that is not in reaction to terror control attacks by the West. While the number of terrorists $x$ along the saddle-point path hardly changes for different growth rates, $\gamma$, the control variables, $w$ and $v$, do. The root of this behavior is the fact that the additional terrorists caused by an increase in $\gamma$ quickly flow through state $x-$ being immediately "translated" into a higher number of attacks $w$. Hence, anything the West can do to make it more difficult for ITO to recruit terrorists translates directly into fewer terror attacks on the West.

To extend the logic above, the single most important factor for determining the size of the terrorist organization, the number of attacks, and the intensity of terror control interventions is the relative value ITO places on attacking the West relative to maintaining its stock of terrorists. If the ratio $d_{2} / d_{1}$ decreases, being strong and powerful $(=x$ large) becomes relatively more important to ITO than is actually attacking the West ( $=w$ large). If $x$ and $w$ are valued equally $\left(d_{2} / d_{1}\right)$, the long-run equilibrium stock of terrorists, is almost identical to the carrying capacity of terrorists $(x=1)$ and $w$ is extremely low (see Figure 7). 


\subsection{Implications of Varying $c_{3}$ for the Infinite Horizon Game}

So far we have assumed that the cause of ITO was not motivated by any political objective (i.e., $d_{3}=0$ ). Suppose, however, ITO derives value by eliciting an over-reaction from the West that turns the "Arab street" against the West (or a pro-western Arab regime). In this case $d_{3}>0$. If the West is aware of this change in the policy goals, but does not adapt its strategy by increasing $c_{3}$ above zero, then the solution is quite insensitive to changes in the value of $d_{3}$. In the long-run the stock of terrorists $x$ is only slightly smaller for $d_{3}>0$ than for $d_{3}=0$. (E.g., increasing $d_{3}$ from 0 to 100 increases $\hat{x}$ by only $7.2 \%$.) Moreover, $d_{3}$ doesn't drive up $w$ beyond $d_{3} / \beta \pi_{2}$ which could cause additional terror control measures.

This implies an important insight. Even if $d_{3}$ changes a lot, the terrorist's actions $(w)$ do not change very much. If we assume the West had no clear independent knowledge about ITO's real objectives, the West could not effectively discern what ITO's objectives are merely by observing its actions. The pattern of attacks that would be optimal for ITO if it were trying to elicit an over-reaction from the West would be very similar to the pattern of attacks it would pursue even its only goals were more simply to kill Westerners and increase its own size.

\section{Conclusions and Suggestions for Further Research}

According to this model, whether the intensity of the terror war grows or ebbs in the long run (i.e. for an infinite time horizon) just depends on how much ITO built up its forces before initiating the conflict. If ITO waited until its initial stock of terrorists exceeded the long-run equilibrium, then the opening rounds of warfare would be the most intense, with the intensity ebbing toward the long-run stable equilibrium (in the case of an infinite time horizon). Conversely, if ITO launched the war while still small, its forces and attack rate would grow toward that equilibrium.

In the short run the situation is different. The intensity of terror attacks and counter terror efforts might ebb then subsequently increase or vice versa, depending on the relative magnitudes of the initial number of terrorists, the long-run equilibrium number, the length of the time horizon, and the shadow price of a terrorist at the end of the time horizon.

The West has the ability to significantly squeeze size, strength and attack rate of ITO for brief periods of time - supported or exacerbated by the shadow price of an additional terrorist at the end of the war. Nevertheless, the West has limited capacity to bring about a cessation of hostilities through its dynamic counter terror efforts.

If one views the West as being additionally able to manipulate certain parameter values (e.g. by increasing the efficiency of terror control activi- 
ties) as well as its current terror control strategy, the analysis is less depressing for the West. Inasmuch as the war on terror is more realistically represented by a chain of short-term (= finite horizon) games instead of a single finite or infinite time horizon game, parameter changes are possible.

The level of terrorism seems sensitive to two sets of parameters in particular. The first govern recruitment in peacetime and its response to counter terror operations. In brief, the harder it is for ITO to recruit, the fewer terror attacks it can commit.

More subtly, ITO will also moderate its terror attacks the more it values maintaining a stock of terrorists in the present or at the end of the time horizon, relative to how much value it derives from committing terrorist attacks.

If ITO's objectives primarily revolve around killing Westerners, that might suggest "target hardening" investments in homeland defense. However, ITO's objectives may not be so straightforward. (Indeed, the very ambiguity of Al-Qaeda's objectives figured into the solution concept we applied to this strategic interaction.)

An interpretation of Al-Qaeda's strategic goals is that it has more conventional political objectives $[3,14]$ so that not only is "war an extension of diplomacy by other means," but also fatwah-endorsed international terror can be an extension of diplomacy by other means. It is not hard to list political objectives whose accomplishment might bring satisfaction to AlQaeda's leadership: evacuation of Western military units from Arab lands, notably Saudi Arabia; the destruction of Israel; the closing of international trade, particularly of popular fashions that are seen as destructive to traditional Muslim values; replacing "moderate" or "pro-Western" regimes with theocracies that adhere more strictly to Muslim Holy law (Sharia), and deposing the House of Saud.

The view that Al-Qaeda is driven by political objectives is vociferously rejected by some [13] and might seem contradicted by the fact that at least until the eve of the 2004 presidential election Al-Qaeda had not issued demands. The absence of a quid pro quo framing does not, however, necessarily imply that Al-Qaeda's attacks on the West are not a means to some other end. It is at least a theoretical possibility that Al-Qaeda is trying through terror to induce the West into taking actions that it would not or could not agree to explicitly in a negotiation. So the absence of political demands from Al-Qaeda does not imply the absence of political objectives. Elaborating on the actors' objectives and knowledge and understanding of their opponents' objectives is a sensible area for further research. It is not inconsistent with Frey and Luechinger's [12] suggestion that making terrorist attacks less attractive (for the terrorists) can be superior to deterrence. ${ }^{11}$ This certainly opens a wide field of further research.

\footnotetext{
${ }^{11}$ Frey and Luechinger [12] contrast the potential benefits of "benevolence" versus
} 
Other extensions of the analysis presented here are more methodological. They include issues like an explicit treatment of time delays in the controls and/or recruiting process. Moreover, it is plausible to assume that the model outcomes might change with the solution concept chosen for the analysis. For example, a classic Stackelberg game might lead to different policy recommendations for the West. More generally, one would ideally like to investigate the dynamic game on terror in all the game variants (Nash vs. Stackelberg, open-loop vs. closed loop, etc.). Analyzing dynamic games is, however, quite difficult. Therefore, future research might include numerical approximation of the Terror War by using available software (e.g., DYNGAME [21], OPTGAME [2], and the Pakes and McGuire's computer algorithm [22]).

\section{Acknowledgements}

This research was partly financed by the Austrian National Bank (OeNB) under contract No. 10107 and contract No. 11216. Special thanks to Fouad ElOuardighi, Harri Ehtamo, Dieter Grass, Steffen Jørgensen, Peter M. Kort, Gerhard Sorger, Franz Wirl, Georges Zaccour, and an anonymous referee for their helpful comments.

\section{APPENDIX}

\section{A.1 Parameterization}

Here we provide rationales that we hope yield parameter values of the right order of magnitudes (given by Table 1). The parameter that is the easiest to interpret is the social discount rate $r$. It is common in policy analysis to assume a real annual discount rate of $3-5 \%$ [15]. We take the high end of this range $(r=0.05)$ inasmuch as war has an urgency that domestic policy does

\footnotetext{
"deterrence" strategies to dissuade terrorists from violent activities. A deterrence strategy, as they use the term, raises the opportunity cost of terrorist activities by defending potential targets, hitting terrorist training centers, infiltrating terrorist groups, and the like. Such deterrence is fundamentally confrontational. A benevolence strategy also raises the opportunity cost of terrorist violence, but it does so by reducing the cost of non-violent activity, or what Frey and Luechinger call "ordinary activity." Unlike a deterrence strategy, however, a benevolence strategy can improve the well-being of terrorists (if they have more ordinary goods) and the public (if less terrorism occurs). In this way, a benevolence strategy has the potential to achieve a positive-sum outcome. A crucial assumption in this analysis is that terrorists' goal is to have more goods. If their objectives were different, e.g., if it were simply to harm the public, than Frey and Luechinger's conclusions might not pertain.
} 
not. One could argue that perhaps ITO's discount rate should be higher than that of the West inasmuch as ITO's objectives are driven more by a single person (Osama bin-Laden) whereas national security objectives are, ultimately, defending a constitutional system of government whose lifespan exceeds that of any mortal human being. Nevertheless, such changes are unlikely to make a major difference.

The parameter $\mu$ is also easy to define. It is the number of terrorists lost per terrorist sent on a successful attack mission. In the absence of terror control measures that figure is basically 1 , inasmuch as ITO frequently uses suicide attack tactics. (For these purposes the September $11^{\text {th }}$ attacks could be viewed as 19 attacks on one day since 19 Al-Qaeda operatives died in that one combined attack.)

The larger $v$ is, the more people ITO loses per successful attack. Parameter $\beta$ governs by how much more. I.e. $\beta$ denotes the ratio of ITO operatives lost per successful attack when the West is on full counter-offensive status vs. peacetime status. We have no empirical information on this parameter, but we can imagine that ITO might lose an order of magnitude more operatives per successful attack if the West were exerting maximum sustainable terror control effort, i.e. $v=1$ ), so in the base case we set $\beta=10$, but also consider values of 5 and 20 .

Parameter $\gamma$ governs how quickly ITO would grow toward its natural size during peacetime (i.e., when $w=v=0$ ). The maximum rate of growth occurs when $x=0.5$ and that rate is $\gamma / 4$. Likewise the time necessary to grow over a certain range (say, from $20 \%$ of its final size to $80 \%$ of that size) can be readily computed. Values in the range $1<\gamma<3$ generate reasonable rates of growth in this regard. They imply growth from $20 \%$ to $80 \%$ of final, peace-time size in a bit less than $1-3$ years. Values of $\gamma=1.5$ and 2 might be the most sensible point estimates.

Given $\gamma$ we can estimate $\alpha$ if we view $v=1$ as the maximum sustainable terror control effort and have some judgment about how such efforts would increase ITO's popularity among its potential recruits. In particular, consider the hypothetical question, how large would ITO get given the indirect recruitment benefits generated by maximum sustainable counter-strike if those counter-strike efforts were not simultaneously eliminating terrorists? That is, imagine a world in which potential recruits were as angry with the US as they would be if the West were attacking Al-Qaeda with all means available, but those attacks were not in fact depleting the population of terrorists?

The state equation for that hypothetical thought experiment would be $\dot{x}=\gamma(1-x) x+\alpha v^{2}$. The equilibrium values of $x$ in that case would be $\hat{x}_{1,2}=$ $0.5\left(1 \pm \sqrt{1+4 \hat{v}^{2} \alpha / \gamma}\right)$. So if one thought the level of anti-West hostility associated with such attacks would double ITO's "peacetime" natural size, then the term $\sqrt{1+4 \alpha / \gamma}=3$, so $\alpha / \gamma=2$. More generally, if one thought it 
would increase ITO's peacetime natural size by a factor of $k$, then $\alpha=k(k-$ 1) $\gamma$. There is abundant room for disagreement about how much animosity terror control operations generates and what role such animosity plays in ITO's recruiting success. We are not experts in such matters, but explore the implications of there being a doubling or tripling of ITO's size, i.e., $\alpha=2 \gamma$ and $\alpha=6 \gamma$.

The last remaining state equation parameter is $\phi$, the rate at which terror control operations would deplete ITO operatives if those operations were pursued with maximum sustainable intensity (i.e., if $v=1$ ). We take as our base case that $\phi=0.5$, implying that if ITO started at its steady state peace time size and never received any new recruits, it would take the West two years of maximum intensity terror control operations to effectively destroy ITO. Once again we are not aware of empirical data with which to estimate this parameter, and we do not have deep domain knowledge, so this value is little more than a guess. We also consider values of $\phi=0.25$ and $\phi=1.0$.

Turning to the objective function values, we normalize relative to the value of $d_{1}$, the benefit per year to ITO of having its full (peacetime) complement of operatives available to it as a resource. I.e., without loss of generality, we set $d_{1}=1$.

The conventional interpretation of ITO's objective is to kill Westerners. For such purposes, the mere existence of a pool of ITO operatives is not of much direct value. They represent potential, but the actual "value" is created by carrying out successful terrorist attacks $(w)$, so in Case 1 we assume $d_{2}$ is much larger than $d_{1}$, in particular $d_{2}=20$. One way to think about that value is that an individual ITO operative generates as much value for the organization by blowing himself or herself up in a terrorist attack as he or she would if $\mathrm{s} /$ he remained in the organization, in reserve, as a perpetual threat never exercised (since $1 / r=20$ when $r=0.05$ ).

In the absence of political motives the ITO player does not value terror control operations per se, so $d_{3}=0$. In the alternative view, those terror control operations are valued, so we also explore the case of $d_{3}>0$. A parameter value of $d_{3}=20$ means that one year of the West exerting maximum sustainable terror control effort is worth as much to ITO's objectives as having its full peacetime complement of operatives in perpetuity. To complete the contrast between the two interpretations of ITO's objectives, when $d_{3}=20$ we set $d_{2}=0$ (i.e., killing Westerners is purely a means to an end, not an end in and of itself). We use the same relative magnitudes of objective function coefficients for the West.

Without any restriction to generality we assume that the "war" on terror is limited to a time-period of half a year, $T=0.5$. 


\section{REFERENCES}

[1] Başar, T., Olsder, G.J. (1999) Dynamic Noncooperative Game Theory. SIAM Series in Classics in Applied Mathematics, Philadelphia, PA.

[2] Behrens, D.A., Hager, M., Neck, R. (2003) OPTGAME 1.0: A numerical algorithm to determine solutions for two-person difference games. In: R. Neck (ed.), Modelling and Control of Economic Systems 2002, Elsevier: Oxford, pp. 47-58.

[3] Bergman, P.L. (2001) Holy War Inc.: Inside the Secret World of Osama bin Laden. Free Press, New York.

[4] Caulkins, J.P., Grass, D., Feichtinger, G., Tragler, G. (2005) Optimizing Counter-Terror Operations: Should One Fight Fire with "Fire" or "Water"? Research Report, Research Unit for Operations Research and Nonlinear Dynamical Systems, Vienna University of Technology.

[5] Dockner, E., Jorgensen, S. Long, N.V., Sorger, G. (2000) Differential Games in Economics and Management Science. Cambridge University Press, Cambridge.

[6] Ehtamo, H., Hämäläinen, R.P. (1986) On Affine Incentives for Dynamic Decision Problems. In: Başar, T. (ed.), Dynamic Games and Applications in Economics. Springer, Berlin, 46-63.

[7] Ehtamo, H., Hämäläinen, R.P. (1989) Incentive Strategies and Equilibria for Dynamic Games with Delayed Information. Journal of Optimization Theory and Applications 63, 355-370.

[8] Ehtamo, H., Hämäläinen, R.P. (1993) A Cooperative Incentive Equilibrium for a Resource Management Problem. Journal of Economic Dynamics and Control 17, 659-678.

[9] Feichtinger, G., Hartl, R.F. (1986) Optimale Kontrolle Ökonomischer Prozesse - Anwendungen des Maximumprinzips in den Wirtschaftswissenschaften. DeGruyter, Berlin.

[10] Frey, B.S., Luechinger, S. (2003) How to Fight Terrorism: Alternatives to Deterrence. Defence and Peace Economics 14(4), 237-249.

[11] Friedman, Thomas L. (2002) Longitudes and Attitudes: Exploring the World after September 11. Farrar, Straus, and Giroux, New York.

[12] Glain, Stephen. (2004) Mullahs, Merchants, and Militants. St. Martin's Press, New York.

[13] Gold, M.R., Siegel, J.E., Russell, L.B., Weinstein, M.C. (1996) CostEffectiveness in Health and Medicine. Oxford University Press. 
[14] Heymann, P.B. (2003) Dealing with Terrorism after September 11, 2001: An Overview. In: Howitt, A., Pangi, R. (eds.) Preparing for Domestic Terrorism. MIT Press, Cambridge, MA, 57-72.

[15] Kaplan, E.H., Mintz, A., Mishal, S., Samban, C. (2005) What Happened to Suicide Bombings in Israel? Insights from a Terror Stock Model. Studies in Conflict \&3 Terrorism 28, 225-235.

[16] Keohane, N.O, Zeckhauser, R. (2003) The Ecology of Terror Defense. Journal of Risk and Uncertainty 26, 201-229.

[17] Léonard, D. (1981) The Signs of the Costate Variables and Sufficiency Conditions in a Class of Optimal Control Problems. Economic Letters 8, 321-325.

[18] Léonard, D., Long, N.V. (1992) Optimal Control Theory and Static Optimization in Economics. Cambridge University Press.

[19] McKibbin, W., Sachs, J.D. (1991) Global Linkages. Macroeconomic Interdependences and Cooperation in the World Economy. The Brookings Institution: Washington, DC.

[20] Pakes, A., Gowrisankaran, G., McGuire, P. (1993): Implementing the Pakes-McGuire Algorithm for Computing Markov-Perfect Equilibria in GAUSS. Working paper of the Department of Economics at the Yale University. 